\title{
SISTEM CUSTOMER SERVICE PT KERETA API INDONESIA (PERSERO) BERBASIS CHATBOT MENGGUNAKAN KOMPUTASI BAHASA
}

\author{
Nia Shafira ${ }^{\bowtie}$, Etin Martiana, Rengga Asmara \\ Program Studi D4 Teknik Informatika, Politeknik Elektronika Negeri Surabaya, Indonesia \\ Email: nia.shafira26@gmail.com
}

DOI: $\underline{\text { https://doi.org/10.46880/jmika.Vol5No1.pp37-41 }}$

\begin{abstract}
As the main train service provider company in Indonesia, PT Kereta Api Indonesia (PT KAI) has many customers who need information. In order to maintain customer loyalty, PT KAI must respond quickly and be adaptive to technology to provide the best service to customers. Limited human resources make PT KAI unable to serve customers simultaneously, so customers often have to wait for a response. In order to provide the best service, automatic messages are needed in order to help customer service performance respond quickly and at the same time with no cost, access anytime and anywhere. This study proposes a new approach with chatbots as a medium for conveying automatic information quickly and simultaneously. This chatbot is made with a computational language that focuses on natural language modeling and cosine similarity as a method for calculating the proximity of inputs and databases. This research can help PT KAI's customer service workers to answer customer needs automatically.
\end{abstract}

Keyword: Customer Service System, Chatbot, Language Computation, Cosine Similarity.

\section{ABSTRAK}

Sebagai perusahaan utama penyedia jasa kereta api di Indonesia, PT Kereta Api Indonesia (PT KAI) memiliki banyak pelanggan yang membutuhkan informasi. Demi menjaga loyalitas pelanggan, PT KAI harus memberikan respon cepat dan bersikap adaptif terhadap teknologi untuk memberikan layanan terbaik kepada pelanggan. Keterbatasan sumber daya manusia membuat PT KAI tidak bisa melayani pelanggan secara bersamaan, sehingga pelanggan seringkali harus menunggu untuk mendapatkan respon. Demi memberikan pelayanan terbaik, pesan otomatis dibutuhkan agar dapat membantu kinerja customer service menjawab secara cepat dan dalam waktu bersamaan dengan tanpa biaya, akses kapanpun dan dimanapun. Penelitian ini mengajukan pendekatan baru dengan chatbot sebagai media untuk menyampaikan informasi otomatis secara cepat dan bersamaan. Chatbot ini dibuat dengan komputasi bahasa yang fokus pada pemodelan natural language dan cosine similarity sebagai metode untuk menghitung kedekatan input dan database. Penelitian ini dapat membantu pekerja customer service PT KAI untuk menjawab kebutuhan pelanggan secara otomatis.

Kata Kunci: Sistem Pelayanan Pelanggan, Chatbot, Komputasi Bahasa, Cosine Similarity.

\section{PENDAHULUAN}

Transportasi merupakan pendukung setiap kegiatan manusia yang terkait mobilisasi barang maupun manusia dalam kehidupan. Di Indonesia kita mengenal tiga jenis transportasi yang digunakan, yaitu transportasi udara, laut dan darat. Kereta api merupakan salah satu moda angkutan darat yang memiliki banyak keunggulan, yakni dapat mengangkut banyak orang dalam sekali perjalanan atau bersifat masal, irit bahan bakar, efisien, hemat pemakaiaan lahan serta ramah lingkungan.

Berdasarkan data dari Badan Pusat Statistik, jumlah penumpang Kereta Api Indonesia pada bulan Febuari 2020 mencapai 32.286 jiwa (Badan Pusat Statistik, 2020). Banyaknya jumlah penumpang kereta api menuntut PT Kereta Api Indonesia (Persero) untuk terus memperbaiki diri di berbagai sektor. Sebagai perusahaan yang bergerak di bidang jasa, sektor layanan pun tak luput dariperhatian perusahaan. Dalam usahanya untuk memberikan layanan terbaik, PT KAI juga harus beradaptasi pada perkembangan zaman dalam memberikan fasilitas layanan kepada para pelanggan.

Sebagai perusahaan besar, tentu saja PT KAI memiliki banyak pelanggan yang membutuhkan informasi, namun customer service yang disediakan oleh PT KAI mengharuskan pelanggan untuk menunggu mendapatkan giliran pelayanan, terbatas akan jam kerja, memungkinkan terjadi human error. Terbatasnya sumber daya pekerja menyebabkan PT 
KAI tidak dapat melayani seluruh pelanggan secara bersamaan dalamsatu waktu, sehingga pelanggan harus mengantriuntuk mendapatkan informasi yang dibutuhkan. Jam aktif berkerja juga menjadi salah satu permasalahan pada layanan perusahaan PT KAI karena layanan yang ditawarkan membutuhkan tenaga manusia yang harus stand-by dalam melayani pelanggan.

Pada penelitian ini, dibuat fitur baru berbasis chatbot untuk memberikan fasilitas pelayanan kepada konsumen PT KAI tanpa batasan ruang dan waktu. Chatbot inidibangun dengan komputasi bahasa yang bertujuan agar pengguna merasa familiar dengan teknologi chatbot serta mudah dalam berkomunikasi dengan menggunakan bahasa indonesia formal maupun non-formal kepada sistem sehingga dapat tercipta pola komunikasiyang interaktifdan tidakterkesan kaku. Penggunaan chatbot ini juga dipilih agar banyak konsumen yang bisa dilayanidalam satu waktu tanpa perlu menunggu. Adapun fitur-fitur pada chatbot iniantara lain: pencarian informasi umum, cek jadwal kereta api dan juga pemesanan tiket kereta api melalui marketplace Tokopedia.

\section{STUDY PUSTAKA}

\section{PT Kereta Api Indonesia (Persero)}

PT Kereta Api Indonesia (PT KAI) adalah perusahaan BUMN yang melayani jasa transportasi umum kereta api. Berpusat di kota Bandung, perusahaan ini tersebar di Pulau Jawa dan Sumatera. Jasa angkutan darat ini disukaioleh masyarakat karena dianggap memiliki keunggulan dibandingkan dengan sarana transportasilainnya, diantaranya adalah memiliki jadwal yang jelas, memiliki jalur sendiri berupa rel, harga tiket yang cenderung murah, dan juga bisa diandalkan sebagai salah satu solusi macet yang makin menjamur di Indonesia.PT KAI menyampaikan profil perusahaan melaluilogo yang dimilikinya.

\section{Customer Service}

Customer service adalah pegawai atau karyawan yang sengaja diben-tuk untuk memberikan informasi kepada calon konsumen dan konsumen. Untuk meningkatkan jumlah konsumen dan menghadapi persaingan bisnis, setiap perusahaan menggunakan berbagai cara dalam memberikan pelayanan kepada konsumennya. Dengan adanya perkembangan teknologi, perusahaan juga dapat memaksimalkan peran customer service (Nugroho, Adi, \& Gumelar, 2020). Saat ini, PT KAI menggunakan berbagai macam customer service seperti jasa customer service officer, customer service call center dan customer service online.

\section{Penelitian Terkait}

Beberapa penelitian yang dijadikan penulis sebagai dasar dalam melakukan penelitian ini diantaranya perancangan chatbot e-commerce dalam menjawab pertanyaan pelanggan (Bhawiyuga, Fauzi, Pramukantoro, \& Yahya, 2017), penggunaan asisten virtual dalam pelayanan pelanggan pada PT. Telkomsel (Perdana \& Irwansyah, 2019), penggunaan chatbot dengan dialogflow dan messenger untuk pelayanan pada e-commerce (Oktavia, 2019), perancangan aplikasi milki bot terintegrasi dengan web CMS untuk customer service pada UKM MINSU (Imamah \& Dores, 2018) dan perancangan helpdesk pada sistem informasi terpadu di Universitas Sam Ratulangi (Benedictus, Wowor, \& Sambul, 2017).

\section{METODE PENELITIAN}

\section{Studi Literatur}

Studi literatur merupakan langkah awal dalam pengerjaan proyek akhir ini. Tahapan ini merupakan tahap penting untuk mempelajari teori-teori serta konsep teknis maupun non-teknis yang menunjang dalam pengerjaan proyek akhir ini. Literatur yang penulis gunakan adalah pembahasan mengenai kekurangan pada sistem customer service, studi terkait layananlayanan yang telah diberikan oleh PT KAI, metode untuk mendapatkan jawaban yang tepat sebagai respon chatbot kepada pengguna.

\section{Pengumpulan Data}

Tahap ini akan dilakukan pengumpulan data yang diperlukan untuk mendukung pengerjaan proyek akhir. Data yang dibutuhkan antara lain; data pertanyaan serta jawaban yang biasa dilontarkan oleh pengguna kereta api, data terkait profil perusahaan, data mengenai jadwal kereta api. Data tersebut didapatkan dariberbagai sumber.

\section{Perancangan Sistem}

Setelah melakukan studi literatur dan pengumpulan data, maka tahap selanjutnya adalah perancangan sistem. Perancangan sistem pada proyek akhir ini meliputi perancangan database, perancangan chatbot menggunakan text mining, perancangan interface dan perancangan web admin.

\section{Implementasi Sistem}

Pada tahap ini, penulis mengimplementasikan sistem yang telah dirancang pada tahap perancangan sistem untuk selanjutnya diimplementasikan kedalam 
bentukaplikasi. Pada tahap implementasi ini, penulis memanfaatkan LINE Messenger sebagai platform chatbot.

\section{Pengujian dan Analisis}

Pada tahap ini, penulis melakukan pengujian terhadap sistem yang telah diimplementasikan pada tahap implementasi sistem. Pengujian dilakukan dengan menguji ketepatan jawaban serta membandingkan sistem yang telah dibuat dengan tujuan yang ingin dicapai. Setelah itu, analisis dilakukan untuk mengetahui apakah sistem sudah berhasil mengatasi masalah.

\section{HASIL DAN PEMBAHASAN \\ Perhitungan Cosine Similarity}

Dalam menghitung kedekatan dua kalimat, antara input user dan data yang ada pada database, penulis menggunakan metode cosine similariy. Pengujian proses perhitungan cosine similarity ini diperlukan agar dapat menganalisa, apakah jawaban chatbot telah sesuai dengan nilai cosine yang tertinggi.

Tabel 1. Sample Perhitungan Cosine

\begin{tabular}{|c|c|c|}
\hline $\begin{array}{l}\text { Input } \\
\text { User }\end{array}$ & Data di Database & Nilai Cosine \\
\hline \multirow{4}{*}{ Kereta } & $\begin{array}{l}\text { Railmin, kereta- } \\
\text { kereta lain } \\
\text { kapan beroperasi } \\
\text { lagi? }\end{array}$ & 0.816496580928 \\
\hline & $\begin{array}{l}\text { Apakah yang } \\
\text { disebut Kereta } \\
\text { Lokal? }\end{array}$ & 0.408248290464 \\
\hline & $\begin{array}{l}\text { Kereta } \\
\text { joglosemar } \\
\text { mulai beroperasi } \\
\text { kapan } \\
\text { @KAI121? }\end{array}$ & 0.316227766017 \\
\hline & $\begin{array}{l}\text { @KAI121 } \\
\text { kereta lokal } \\
\text { rangkas-merak }\end{array}$ & 0.288675134595 \\
\hline
\end{tabular}

Sesuai hasil dari tabel 1, dapat disimpulkan bahwa fungsi perhitungan cosine similarity telah berjalan dengan semestinya pada sistem, karena sistem memberikan jawaban sesuai nilai cosine yang tertinggi. Selain itu, dari studi kasus di atas, didapati bahwa panjang pendeknya kalimat berpengaruh pada score cosine similarity, kalimat yang dimaksud adalah gabungan antara kalimat input maupun kalimat yang ada padadatabase.

\section{Unit Testing}

Pengujian unit memiliki tujuan untuk mengetahui apakah chatbot dapat memberikan jawaban secara benar ketika diberi input.

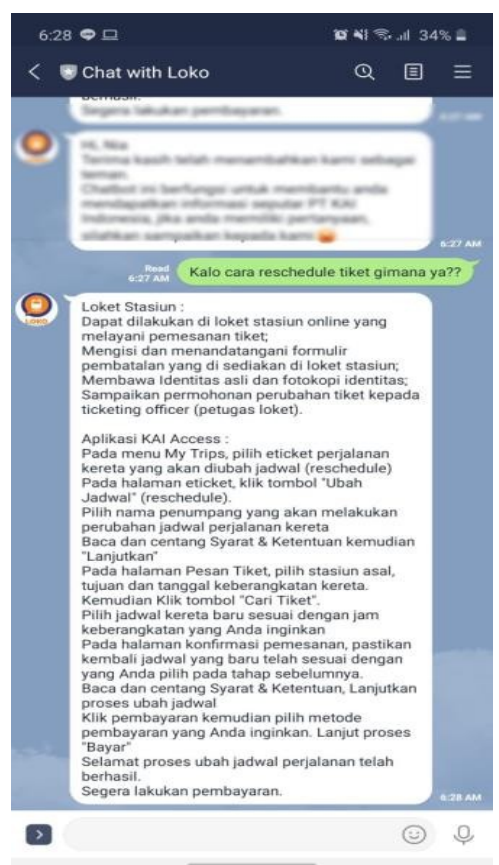

Gambar 1. Sample Percakapan 1

Chatbot telah memiliki pengetahuan seputar reschedule tiket kereta api pada database. Pada gambar 1 terlihat bahwa chatbot menjawab sesuai konteks, meski input yang diberikan bukan berupa kalimat formal maupun kalimat terformat.

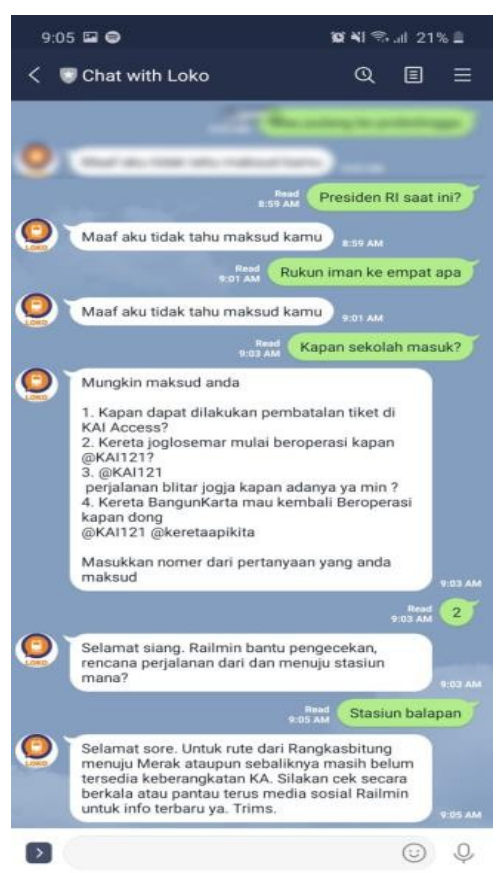

Gambar 2. Sample Percakapan 2 
Chatbot diberi inputan diluar topik KAI, sehingga tepat jika chatbot tidak memberikan jawaban (tidak mengerti maksud input). Namun ketika didapati kata yang sama seperti kata "kapan", chatbot akan memberi respon seperti pada gambar 2. Jika diselidiki lagi, saat user memilih "2", chatbot seakan-akan memberikan pertanyaan lanjutan, namun sebenarnya itu bukanlah pertanyaan berantai, respon chatbot merupakan data twitter hasil crawling yang merupakan reply dari admin@kai121 terhadap tweet mention yang didapat. Sehingga saat user hendak menjawab pertanyaan chatbot, chatbot akan menganggap hal tersebut sebagai inputan baru. Dari kasus ini, dapat dipelajari bahwa tidak semua data twitter@kai121 siap digunakan.

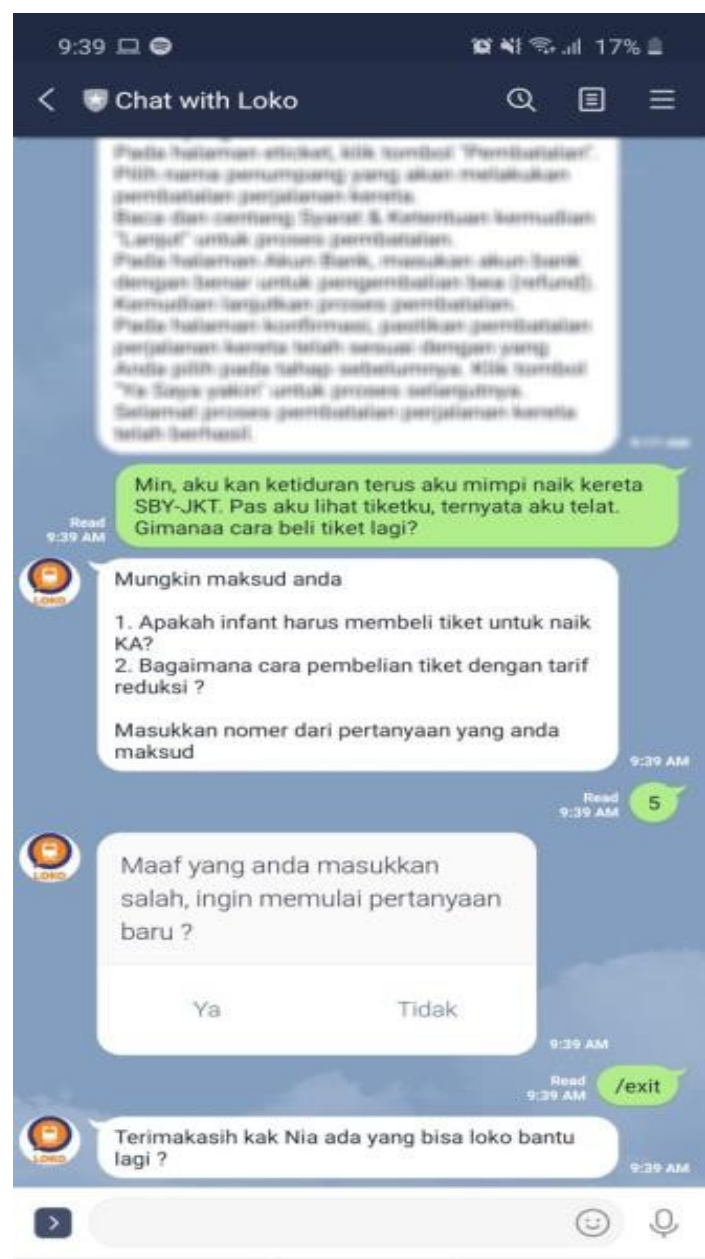

Gambar 3. Sample Percakapan 3

Proses pencarian jawaban yangdilakukan oleh chatbot adalah dengan menghitungkesamaan kata yang muncul, sehingga ketika chatbot diberi inputan kompleks seperti pada gambar 3, chatbot tidak bisa memahami bahwa inti dari pertanyaan di atas adalah "cara membelitiket".

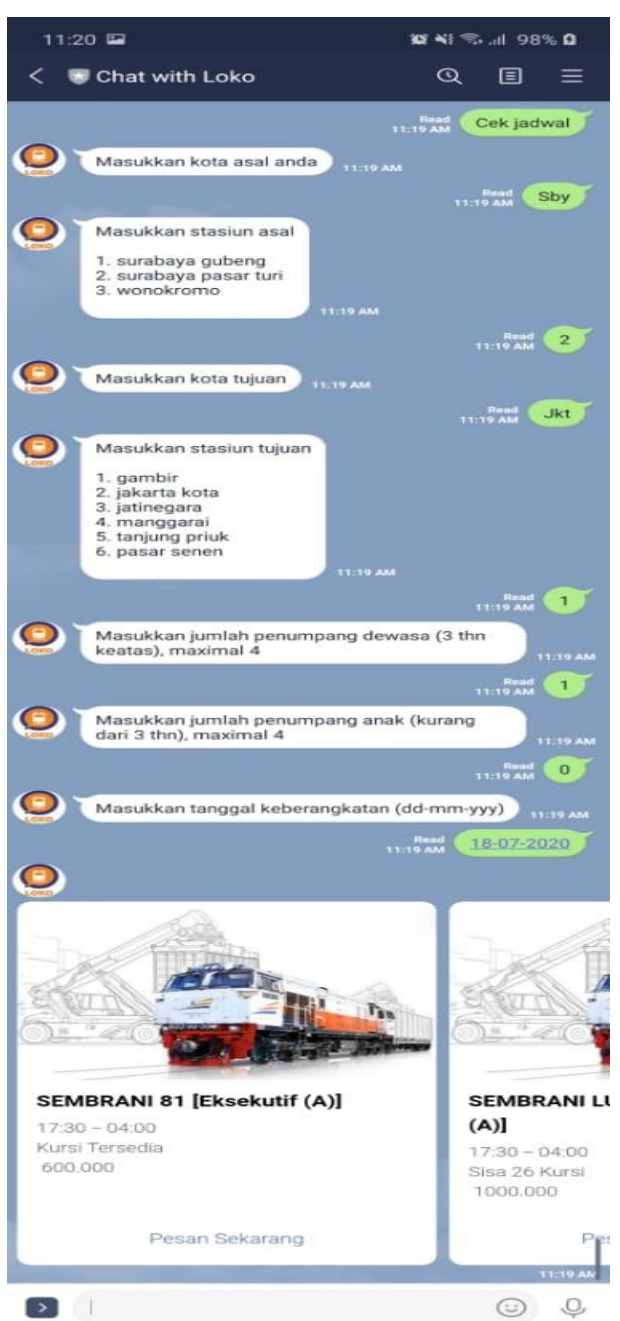

Gambar 4. Sample Pertanyaan Jadwal

Mencarijadwalkereta Surabaya - Jakarta dengan beda stasiun, sehingga jadwal dapat ditemukan. Setelah jadwalberhasil muncul,proses pemesanan akan dilempar ke website Tokopedia, sehingga hasil dariklik "Pesan Sekarang".

\section{Perhitungan Error Rate}

Sistem juga telah diuji dengan banyak varian inputan, diambil 120 data sampling untuk perhitungan errorrate.

Tabel 2. Perhitungan Error Rate

\begin{tabular}{|l|l|}
\hline Testing Query & 120 \\
\hline Processed & 120 \\
\hline True Answer & 89 \\
\hline Wrong Answer & 31 \\
\hline Error Rate & $74,167 \%$ \\
\hline
\end{tabular}




\section{KESIMPULAN}

Kereta api merupakan salah satu moda angkutan darat yang memilikibanyak keunggulan, yakni dapat mengangkut banyak orang dalam sekali perjalanan atau bersifat masal, irit bahan bakar, efisien, hemat pemakaiaan lahan serta ramah lingkungan. Berdasarkan data dari Badan Pusat Statistik, jumlah penumpang Kereta Api Indonesia pada bulan Febuari 2020 mencapai 32.286 jiwa. Banyaknya jumlah penumpang kereta api menuntut PT Kereta Api Indonesia (Persero) untuk terus memperbaiki diri di berbagai sektor, terutama sektor pelayanan pelanggan agar dapat menjangkau pelanggan dimanapun dan kapanpun.

Pada penelitian ini, penulis telah menerapkan bidang ilmu komputasi bahasa dalam pembuatan chatbot melalui proses text mining serta proses pengecekan sinonim. Secara keseluruhan, sistem telah berjalan sebagaimana mestinya, akurasi chatbot mencapai $74 \%$ dengan rata-rata waktu respon mencari 11 detik. Kehandalan chatbot sangat bergantung pada proses text mining, sehingga untuk membuat chatbot yang mengerti alami bahasa manusia, diperlukan untuk selalu memperkaya serta mengupdate kata dalamkamus stopword list dan juga kamus sinomim.. Penggunaan data twitter sebagai sumber pengetahuan chatbot tidak serta merta dapat langsung digunakan, diperlukan filtering data sebelum data disimoan ke dalam database.

\section{DAFTAR PUSTAKA}

Badan Pusat Statistik. (2020). Jumlah Penumpang Kereta Api. Retrieved from https://www.bps.go.id/

Benedictus, R. R., Wowor, H., \& Sambul, A. (2017). Rancang Bangun Chatbot Helpdesk untuk Sistem Informasi Terpadu Universitas Sam Ratulangi. E-Journal Teknik Informatika, 11(1), $1-7$.

Bhawiyuga, A., Fauzi, M. A., Pramukantoro, E. S., \& Yahya, W. (2017). Design of E-Commerce chat robot for automatically answering customer question. 2017 International Conference on Sustainable Information Engineering and Technology (SIET), 159-162. IEEE.

Imamah, F., \& Dores, A. (2018). Aplikasi chatbot (milki bot) yang terintegrasi dengan web CMS untuk customer service pada UKM MINSU. Jurnal Cendikia, 16(2), 100-106.

Nugroho, A., Adi, D. P., \& Gumelar, A. B. (2020). Chatbot Untuk Customer Service Berbasis Teks dan Suara pada Sistem Manajemen Pemesanan (OMS) Menggunakan Platform Android. Jurnal
Repositor, 2(6), 683-690.

Oktavia, C. A. (2019). Implementasi Chatbot Menggunakan Dialogflow dan Messenger Untuk Layanan Customer Service Pada E-Commerce. Jurnal Informatika Merdeka Pasuruan, 4(3), 36-40.

Perdana, R. P., \& Irwansyah. (2019). Implementasi Asisten Virtual Dalam Komunikasi Pelayanan Pelanggan (Studi Kasus Pada Layanan Pelanggan Telkomsel). Jurnal Komunikasi, 11(2), 183-196. 